\title{
Introduction to the Special Issue: Highlighting the Best Papers from the OTL SIG AERA 2018
}

\author{
Tadd Farmer and Jennifer Richardson \\ Purdue University \\ Karen Swan \\ University of Illinois - Springfield
}

The American Educational Research Association (AERA) was founded in 1916 to improve education through the design, implementation, and dissemination of research on a variety of educational topics. Each year the AERA annual meeting attracts thousands of students, teachers, and researchers to its annual conference to understand how to improve education through the design, implementation, and dissemination of rigorous educational research. AERA's international reach includes over 25,000 members from more than 96 countries, each member participating in one or more of the 12 divisions and 150 special interest groups. The 2018 conference was held in New York City under the theme of "The dreams, possibilities, and necessity of public education."

The Online Teaching and Learning (OTL) Special Interest Group (SIG) provides a forum within AERA for discussion and reporting on issues and research related to teaching and learning in an online environment. The OTL SIG received 130 proposals for presentations of research at the 2018 annual meeting and accepted 58, making for an accept rate of 45\%, which were instantiated as paper presentations, posters, round table sessions and panel discussions. Research talks were geared towards a wide variety of topics including student perception, engagement, satisfaction, cooperation, activity, discussion, and achievement in online and blended courses. For more information on the OTL SIG, please visit http://www.aera.net/SIG035/Online-Teachingand-Learning-SIG-35).

Since 2016, Online Learning (OLJ) has dedicated a special issue to publish the year's best research from the OTL SIG. This year's special issue presents a diverse selection of high-quality research on a broad range of topics using an array of research methods. The articles in this issue will be arranged according to four major categories related to online learning: pedagogical strategies, student outcomes, student behavior, and course instructional design principles.

The first category of articles includes three studies considering the impact of pedagogical strategies, specifically student interactions. In their study, Peterson, Beymer, and Putnam considered the effects of student interaction on motivation and affective states in the article entitled "Synchronous and Asynchronous Discussions: Effects on Cooperation, Belonging, and Affect." In this study, 52 undergraduate teacher education majors were assigned to either a synchronous or asynchronous small-group discussion format as part of their online course. Identical discussion activities and prompts were given to both groups along with discussion guidelines to enhance group communication. Students' motivation and affective experience was measured through course surveys at the middle and end of the course, and discussion logs were analyzed by length, emotional expression, and discrepancy and certainty statements. While there were no differences 
in positive expression between synchronous and asynchronous groups, the researchers found higher negative expression and higher use of discrepancy and certainty statements within the synchronous group. They concluded that the use of asynchronous communication may prevent students from openly expressing negative or contrary thoughts which the authors deemed necessary for achieving cooperative learning goals and objectives.

In her paper, "Navigating Assigned Roles for Asynchronous Online Discussions: Examining Participants' Orientation Using Conversation Analysis," Amber Warren reports another way of encouraging debate in online discussions. Warren investigated the practice of assigning discussion roles (e.g., Devil's Advocate, Discussion Starter) among online teacher education graduate students. Throughout the course, discussions roles would rotate to give students experience with each role. At the conclusion of the semester, discussion posts were downloaded and analyzed qualitatively using conversation analysis with a focus on the Devil's Advocate and Discussion Starter roles. Through her analysis, Warren found a high level of question-answer interactivity that was notably different from more typical discussion response patterns. She concluded that assigning roles, particularly the Devil's Advocate role, allowed students to pose genuine disagreements and questions that might have gone unasked in the absence of these discussion roles.

In "Exploring the Impact of Small-group Synchronous Discourse Sessions in Online Math Learning," Jinnie Choi and Alyssa Walters explored the impact of small group discourse sessions within the context of elementary mathematics education. Over a one-year period of time, 898 elementary students engaged in at least one discourse session which consisted of a 30-minute synchronous session with a small group of peers and a student-facilitator. During these discourse sessions, students were presented with a math problem, asked to consider multiple ways of approaching the problem, and shared their mathematic reasoning processes with their peers. Data from participants' instrument logs, reflections, and assessments were analyzed using multiple regression to determine whether engaging in math discourse related to students' confidence, attitudes towards math, and math performance. While Choi and Walters found that confidence, self-esteem, and mindset scores did not change with math discourse sessions, they found that students who engaged in these sessions had significantly higher math achievement scores than students who did not participate.

The second category of articles explores student behavior and includes two articles. The first article, "Quiet Participation: Investigating Non-Posting Activities in Online Learning," by Lesley Wilton, investigated the less-visible behaviors of online students. Using mixed-methods to study online graduate student behavior, Wilton collected system data on 137 students, surveyed a sample of 14 students about their perceptions, and interviewed four students to gain a deep understanding of their experience. She found that less active discussion board participants were still actively learning through writing, reading, and rereading despite not engaging as frequently in other, more observable learning behaviors (e.g., text entries). She concluded that "quiet," lessvisible behaviors are important contributors to meaningful learning experiences and should be more consistently supported and evaluated among online students.

In contrast to non-observable behaviors of online students, Fernanda Bonafini examined "super-posters" in her article, "Characterizing Super-Posters in a MOOC for Teachers' Professional Development." In addition to participant demographic click-data, Bonafini analyzed the content of forum posts through content analysis and used social network analysis to understand super-posters patterns of engagement. Bonafini observed that super-posters dramatically expanded 
the network of participation in discussion forums by eliciting replies from peers through new discussion threads and by responding to replies. Her findings provide insight into how these superposters can be identified and suggest that these individuals could be formally used as part of the instructional team to support learning.

Our next category focuses on student outcomes in online courses. In their article, "Digging Deeper into the Data: The Role of Gateway Courses in Online Student Retention," Bloemer, Swan, Day, and Bogle investigated the problem of student retention by analyzing "gateway courses." These foundational courses are typically characterized by high rates of failing scores and often act as barriers to student progress. Using data collected from undergraduate students over a three-year period of time, Bloemer et al. applied binary logistic regression methods to determine significant predictor variables for student grade outcomes. By doing so, they reported that student type, academic stage, cumulative GPA, and previous withdrawals all predict successful outcomes. The authors used these variables to predict percentages of students failing or withdrawing from particular courses and compared predicted DFW rates with actual DFW rates in them. This "gap analysis" method can be used to identify courses with a considerable difference between predicted and actual DFW rates so that limited resources can be used where they are most needed and that courses which are actually over-performing are not subjected to unnecessary, and potentially harmful, intervention.

In their article entitled, "Going the Distance: Course Performance and Motivation of Distance Learning Students," Tiffaney Hobson and Krista Puruhito sought to understand the relationship between motivational factors and student learning. Using data collected from 409 student surveys, they examined motivational constructs such as connectedness, self-efficacy, knowledge building, and instrumentality, and sought to identify relationships between these constructs and student demographics (e.g., gender, major vs. non-major), and the relationship between student demographics and course grades. Through this inquiry, they found that there were statistically significant differences in motivational constructs related to gender (male students reported higher levels of extrinsic goal motivation, for example) and major status (majors had significantly greater self-efficacy than non-majors, for example). Although these motivational differences existed between students with differing major statuses, there were no significant differences between majors and non-major involving course grades. They found that student grades were, however, correlated with the knowledge building and self-efficacy constructs, and suggested that reinforcing students with grades while neglecting other motivational constructs may not be equally effective for all online students.

McClannon, Cheney, Bolt, and Terry look at online community outcomes in their article "Predicting Sense of Presence and Sense of Community in Immersive Online Learning Environments." Using the Sense of Community II index and the Community of Inquiry survey, McClannon et al. investigated the relationship between course factors and these measures within immersive learning environments involving 1053 online graduate students over a seven-year period of time. Immersive environments are technology-rich systems that create authentic, sensory experiences for students via virtual worlds, multiplayer games, or augmented or virtual reality applications. The authors found that cohort type (online or hybrid) and length of time in the program significantly impacted students' sense of presence and community. Additionally, they determined that time spent by students in the immersive environment also had an impact on sense of community. They concluded that immersive environments can lead to greater sense of community and presence. 
The final category of articles explores instructor or instructional designer perspectives as they engage in online course design. In her article entitled "Supporting Literacy with Accessibility: Virtual School Course Designers' Planning for Students with Disabilities," Mary Rice considers strategies K-12 instructional designers use to make their courses accessible for all learners. Through a content analysis approach, Rice analyzed recorded design team meetings, instant message logs, course design templates, and other course design resources to identify frequently used accessibility strategies. As a result, Rice found that three key strategies emerged from the design team, including writing clear learning objectives, personalizing and contextualizing learning, and supporting multiple modalities through visual and audio representations of content. Additionally, this study demonstrates evolution in thinking and understanding accessibility among instructional designers engaged in design activities.

Alex Kumi-Yeboah considers the experience of designing for collaboration among culturally-diverse learners in his article, "Designing a Cross-Cultural Collaborative Online Learning Framework for Online Instructors." Using a qualitative grounded theory approach with 40 online instructors, Kumi-Yeboah identified instructional strategies and challenges in designing collaborative online environments that transcend traditional cultural boundaries. Group work, selfintroductions, globally-diverse content examples, and using computer-supported learning tools (e.g., discussion boards, chat rooms, blogs) were all strategies commonly used by instructors to facilitate greater cultural understanding. Despite these strategies, 32 of the 40 instructors also reported challenges in building cross-cultural collaboration between students including difficulty knowing learner's needs and cultural preferences and navigating language barriers.

In "Instructor Experience Designing MOOCs in Higher Education: Pedagogical, Resource, and Logistical Considerations and Challenges," Zhu, Bonk, and Sari explore the experiences of MOOC instructors in the design of their courses. In this mixed method study, 143 instructors were surveyed and asked about the considerations and challenges of MOOC design. Of these participants, 12 were interviewed to gain a deeper understanding of their experience with MOOC design. Participants revealed several common considerations and challenges in MOOC design in terms of pedagogy (e.g., learning objectives, assessments), resources (e.g., MOOC platform, support), and logistics (e.g., design time). To overcome these challenges, MOOC instructors commonly examined the designs of other MOOCs or sought help from the platform provider, colleagues, or other members from their institution.

One path to improving student retention involves assuring quality in online courses. "Visions of Quality Assurance in Online MBA Programs" by Hinck, Rice, Lowenthal, and Perkins seeks to identify aspects of quality courses using Delphi methodology, using administrators, faculty, and instructional designers with at least 5 years of online learning experience. Through this process, participants reported seven main concepts related to quality programs including academic integrity and rigor, course content, design, and delivery, faculty qualifications and support, quality frameworks, accreditation, learner support, and evaluation. Since administrators, faculty, and instructional designers all have distinct roles, the authors reported differences in priorities and perspectives of quality among the participants. However, all participants valued accreditation for all MBA programs.

We would like to extend our special thanks to OLJ editor-in-chief Peter Shea, OLJ managing editor Sturdy Knight, OTL SIG chair Steven Terrell, and OTL SIG program chair AnaPaula Correia. We hope you enjoy the articles in this special issue as much as we did and find them useful. 
Information about the editors:

- Tadd Farmer, Doctoral Student, Learning Design and Technology program, Curriculum and Instruction Department, Purdue University; farmer32@purdue.edu

- Jennifer C. Richardson, Professor, Learning Design and Technology program, Curriculum and Instruction Department, Purdue University; jennrich@purdue.edu

- Karen Swan, Stukel Professor of Educational Leadership, University of Illinois Springfield; kswan4@uis.edu 